\title{
Clinical value of R-spondins in triple-negative and metaplastic breast cancers
}

\author{
F Coussy ${ }^{1,9}$, F Lallemand ${ }^{1,9}$, S Vacher ${ }^{1}$, A Schnitzler ${ }^{1}$, W Chemlali ${ }^{1}$, M Caly ${ }^{2}$, A Nicolas ${ }^{2}$, S Richon ${ }^{3}$, D Meseure ${ }^{2}$, \\ R El Botty ${ }^{4}$, L De-Plater ${ }^{4}$, L Fuhrmann ${ }^{2}$, T Dubois $^{5}$, S Roman-Roman ${ }^{6}$, V Dangles-Marie ${ }^{4,7}$, E Marangoni ${ }^{4}$ \\ and I Bièche ${ }^{\star 1,8}$
}

${ }^{1}$ Unit of pharmacogenomics, Department of Genetics, Institut Curie, 26 rue d'Ulm, Paris 75005, France; ${ }^{2}$ Department of Biopathology, Institut Curie, 26 rue d'Ulm, Paris 75005, France; ${ }^{3}$ CNRS, UMR 144, Research Center, Institut Curie, 26 rue d'Ulm, Paris 75005, France; ${ }^{4}$ Laboratory of Preclinical Investigation, Department of Translational Research, Institut Curie, 26 rue d'Ulm, Paris 75005, France; ${ }^{5}$ Breast Cancer Biology Group, Department of Translational Research, Institut Curie, 26 rue d'Ulm, Paris 75005, France; ${ }^{6}$ Department of Translational Research, Institut Curie, 26 rue d'Ulm, Paris 75005, France; ${ }^{7}$ Université Paris Descartes, Sorbonne Paris Cité, Paris 75006, France and ${ }^{8}$ EA7331, University Paris Descartes, 4 avenue de l'observatoire, Paris 75006, France

Background: RSPO ligands, activators of the $\mathrm{Wnt} / \beta$-catenin pathway, are overexpressed in different cancers. The objective of this study was to investigate the role of RSPOs in breast cancer (BC).

Methods: Expression of RSPO and markers of various cancer pathways were measured in breast tumours and cell lines by qRT-PCR. The effect of RSPO on the Wnt/ $\beta$-catenin pathway activity was determined by luciferase assay, western blotting, and qRT-PCR. The effect of RSPO2 inhibition on proliferation was determined by using RSPO2 siRNAs. The effect of IWR-1, an inhibitor of the Wnt/ $\beta$-catenin pathway, was examined on the growth of an RSPO2-positive patient-derived xenograft (PDX) model of metaplastic triple-negative BC.

Results: We detected RSPO2 and RSPO4 overexpression levels in BC, particularly in triple-negative BC (TNBC), metaplastic BC, and triple-negative cell lines. Various mechanisms could account for this overexpression: presence of fusion transcripts involving RSPO, and amplification or hypomethylation of RSPO genes. Patients with RSPO2-overexpressing tumours have a poorer metastasis-free survival $\left(P=3.6 \times 10^{-4}\right) . R S P O 2$ and $R S P O 4$ stimulate $W n t / \beta$-catenin pathway activity. Inhibition of RSPO expression in a TN cell line inhibits cell growth, and IWR-1 significantly inhibits the growth of an RSPO2-overexpressing PDX.

Conclusions: RSPO overexpression could therefore be a new prognostic biomarker and therapeutic target for TNBC.

Breast cancer (BC) is the leading cause of death by cancer in women (Jemal et al, 2007). Fifteen percent of primary BC are triple-negative $\mathrm{BC}(\mathrm{TNBC})$ with lack of expression of oestrogen receptor (ER), progesterone receptor (PR), and human epidermal growth factor receptor 2 (Morris et al, 2007). The majority of TNBC are invasive ductal carcinomas, but metaplastic BC (MBC) constitutes a rare subtype $(<1 \%)$. MBC is characterised morphologically by the differentiation of neoplastic epithelium into squamous cells and/or mesenchymal cells. MBC displays a fairly aggressive clinical behaviour, and unlike other forms of TNBC, these tumours do not appear to respond to conventional chemotherapy regimens (Hennessy et al, 2006). Globally, women with TNBC or MBC have a poor prognosis, particularly due to the absence of targeted therapies (Aydiner et al, 2015).

The abnormally high activity of the canonical Wnt/ $\beta$-catenin signalling pathway has a key role in the development of many

\footnotetext{
*Correspondence: Dr I Bièche; E-mail: ivan.bieche@curie.fr

${ }^{9}$ These authors contributed equally to this work.
}

Received 8 December 2016; revised 7 April 2017; accepted 13 April 2017; published online 4 May 2017

(C) 2017 Cancer Research UK. All rights reserved 0007-0920/17 
cancers, such as colorectal cancer (CRC) and BC, particularly TNBC and MBC (Hayes et al, 2008; MacDonald et al, 2009; Bilir et al, 2013; Cai et al, 2013; Maubant et al, 2015). In CRC, Wnt/ $\beta$ catenin pathway activation is predominantly (90\%) due to mutations of $A P C$ and CTNNB1 genes (coding for $\beta$-catenin) (Bienz and Clevers, 2000; Behrens and Lustig, 2004; Seshagiri et al, 2012). However, anomalies of APC and CTNNB1 genes are rare in breast carcinogenesis (Cancer Genome Atlas Network, 2012). Identifying and understanding the mechanisms responsible for activation of the $\mathrm{Wnt} / \beta$-catenin signal in $\mathrm{BC}$ are essential for the development of new biomarkers and therapeutic targets for this type of cancer, particularly TNBC.

The family of RSPO secreted proteins comprises four members (RSPO1-4). RSPOs are physiologically involved in embryogenesis and are ligands for the leucine-rich repeat containing $G$ proteincoupled receptors (LGRs) $4-6$. These proteins synergise with Wnt ligands to activate the $\mathrm{Wnt} / \beta$-catenin pathway by inducing stabilisation of FZD and LRP 5/6 (Jin and Yoon, 2012). Recently, a new mechanism of activation of the $\mathrm{Wnt} / \beta$-catenin pathway has been identified in $10 \%$ of CRC: overexpression of RSPO2 and $\mathrm{RSPO} 3$ due to gene fusions resulting from deletions of about $150 \mathrm{~kb}$ in the chromosome region $8 \mathrm{q} 23$ and chromosome inversions in the region 6q22.3 (involving $R S P O 2$ and $R S P O 3$, respectively). These gene fusions lead to the formation of transcripts involving exon 1 of EIF3E and exon 2 of RSPO2 (EIF3E (exon1)-RSPO2 (exon2)) and transcripts involving either exon 1 or exon 7 of $P T P R K$ and exon 2 of RSPO3 (PTPRK (exon1 or exon7)-RSPO3 (exon2)), resulting from overexpressed functional $\mathrm{RSPO} 2$ and $\mathrm{RSPO} 3$ proteins, respectively (Seshagiri et al, 2012; Shinmura et al, 2014). Expression of these RSPO fusion transcripts is mutually exclusive with $A P C$ and $C T N N B 1$ mutations and could therefore explain activation of the $\mathrm{Wnt} / \beta$-catenin pathway in the $10 \%$ of CRC that do not harbor any APC or CTNNB1 mutation.

RSPO2 and RSPO3 genes were identified as Int, a common integration site of mouse mammary tumour virus (Callahan et al, 2012), and RSPO2 overexpression in mouse mammary epithelial cells induces tumour growth (Klauzinska et al, 2012). These results suggest that overexpression of RSPOs could have a crucial role in breast carcinogenesis.

In the present study, we investigated the potential involvement of RSPO in breast carcinogenesis.

\section{MATERIALS AND METHODS}

Patients and samples. Samples from 446 unilateral invasive primary breast tumours excised from women, managed at Institut Curie (Saint-Cloud, France) between 1978 and 2008, and described in detail elsewhere (Meseure et al, 2016) were analysed. Standard prognostic factors of this tumour set are presented in Supplementary Data (Supplementary Table S1). With a median follow-up of 8.9 years (range: 6 months to 29 years), 171 patients developed metastasis. Ten specimens of adjacent normal breast tissue from $\mathrm{BC}$ patients or normal breast tissue from women undergoing cosmetic breast surgery were used as sources of normal RNA. An additional set of 28 MBCs collected by Institut Curie was analysed by qRT-PCR: 16 were diagnosed as MBC with mesenchymal elements, 4 as $\mathrm{MBC}$ with squamous metaplasia, and 8 as spindle cell carcinoma (Weigelt et al, 2015).

Cell lines. Thirty-two RNA samples from breast cell lines obtained from the American Type Culture Collection (ATCC, Manassas, VA, USA), including 16 triple-negative tumour cell lines, were analysed by qRT-PCR (Supplementary Table S2). The HBCc-15 cell line was established from the HBCx-15 TNBC patient tumourderived xenograft (PDX).
MDA-MB-468, MDA-MB-231, and HEK293 cells were purchased from ATCC. Fibroblast L cells producing Wnt-3a and L cells stably transfected with pGKneo plasmids were a generous gift from Dr Shinji Takada.

Real-time qRT-PCR. Total RNA extraction and RT-PCR have been described previously (Bieche et al, 2001). qRT-PCR results, expressed as $N$-fold differences in $R S P O$ and $L G R$ (or genes of interest involved in various cancer pathways) gene expression relative to the TBP gene and called $N_{\text {target }}$, were determined as $N_{\text {target }}=2^{\Delta \text { Ctsample }}$, where the $\Delta \mathrm{Ct}$ value of the sample was determined by subtracting the average $\mathrm{Ct}$ value of the target gene from the average Ct value of the TBP gene. $N_{\text {target }}$ values of breast tumour samples were subsequently normalised so that the median $N_{\text {target }}$ value for 10 normal breast tissues was equal to 1 . Primers for fusion genes involving $R S P O 2$ and $R S P O 3$ described in the literature (Seshagiri et al, 2012) and for TBP, RSPO1, RSPO4, and LGR4-6 genes were chosen with the assistance of the Oligo 6.0 software (National Biosciences, Plymouth, MN, USA) (Supplementary Table S3 and additional information on request; Bieche et al, 2001).

For the gene expression study in the breast tumour series, the 7 investigated genes (RSPO1-4 and LGR4-6) were differentially expressed in the 10 normal breast tissues analysed. The median $\mathrm{Ct}$ of normal breast tissues was equal to 30.5 for RSPO1, 27.8 for RSPO3, 28.6 for LGR4, and 31.4 for LGR6. mRNA levels of these four genes in breast tumours are expressed relative to the endogenous RNA control TBP, normalised on the basis of normal breast tissue expression (median $N_{\text {target }}$ for normal breast tissues $=1$ ). Values $\geqslant 3$ were considered to represent overexpression. For the other 3 genes (RSPO2, RSPO4 and LGR5), absent $(\mathrm{Ct}>35)$ or low level $(32<\mathrm{Ct}<35)$ expression was observed in the 10 normal breast tissues analysed. Consequently, mRNA levels in breast tissue samples were normalised to obtain a 'basal mRNA level' (smallest amount of mRNA quantifiable $(\mathrm{Ct}=35)$ ) equal to 1 . Values $\geqslant 5$ were considered to represent high expression in breast tumour samples (Bieche et al, 1999; Bieche et al, 2003).

For the gene expression study in breast cell lines and PDX, mRNA levels were normalised to obtain a 'basal mRNA level' (smallest amount of mRNA quantifiable $(\mathrm{Ct}=35)$ ) equal to 1 . Values $\geqslant 5$ were considered to represent high expression in breast tumour samples.

For the TCGA analysis, mRNA expression (RNA sequencing), methylation, and copy number alteration data were downloaded (http://www.cbioportal.org/) for TCGA Breast Cancer (provisional cohort, $n=1105$; Cerami et al, 2012; Gao et al, 2013).

Western blotting. The methods are described in detail elsewhere (Lallemand et al, 2001). In this study, we used the following antibodies: anti-GAPDH (sc-20357, Santa Cruz Biotechnology, Dallas, TX, USA) used as an internal control, polyclonal rabbit anti-phospho LRP6 (ser 1490, Cell Signaling Technology, Danvers, MA, USA), monoclonal rabbit anti-LRP6 (C5c7, Cell Signaling Technology), polyclonal rabbit active $\beta$-catenin (05665, Millipore, Billerica, MA, USA), and anti- $\beta$-catenin (sc-7199, Santa Cruz Biotechnology).

Conditioned medium. Conditioned medium containing Wnt3a (Wnt3a-CM) was prepared as previously described (Shibamoto et al, 1998). To prepare RSPO2- or RSPO4-conditioned medium, $2 \times 10^{6}$ HEK293 cells were seeded in a 94-mm-diameter dishes. Twenty-four hours later, cells were transfected with the empty vector (PS100001, Origene, Rockville, MD, USA), myc-tagged RSPO2 expression vector (RC224177, Origene), or myc-tagged RSPO4 expression vector (RC224295, Origene). To study the effect of RSPO2/4 and Wnt3a on the Wnt/ $\beta$-catenin pathway activity, cells were cultured overnight in medium containing 50\% RSPO medium and/or 30\% Wnt3a. 
The presence of myc-tagged RSPO in conditioned medium was verified by western blotting (Supplementary Figure S1).

Luciferase assays. The methods have been described in detail elsewhere (Lallemand et al, 2001). Firefly luciferase activity was normalised to Renilla luciferase activity and expressed as mean \pm s.d. of triplicates from a representative experiment. Results are shown as fold induction of luciferase activity compared with control cells transfected with empty vectors alone.

Immunohistochemistry (IHC). Paraffin sections of $\mathrm{HBCx}-15$ (xenograft with $\mathrm{RSPO} 2$ overexpression) and $\mathrm{HBCx}-3$ (xenograft without expression of RSPO) TNBC PDX were prepared as previously described (Landemaine et al, 2008). Briefly, PDX blocks were deparaffinised, treated with $3 \% \mathrm{H}_{2} \mathrm{O}_{2}$, and incubated without (negative control) or with goat polyclonal anti-RSPO2 antibody (Santa Cruz Biotechnology). Staining signals were revealed with the Leica bond biosystem (Leica Biosystems Newcastle Ltd, Newcastle-upon-Tyne, UK). Slides were counterstained with Mayer's haematoxylin.

SiRNA inhibition. For siRNA inhibition and real-time monitoring of cell proliferation studies, BT549 cells were seeded at a density of 5000 cells per well in 96-well E-Plates (ACEA Biosciences, San Diego, CA, USA). The in vitro growth curve was characterised by using the xCELLigence system (Roche Inc., Bale, Swiss). Cell were transfected $24 \mathrm{~h}$ later with validated human RSPO2 siRNAs (reference SI04274760 and SI04303957) or negative control siRNA 1 (Qiagen, Hilden, Germany) at a final concentration of $30 \mathrm{nM}$ in the presence of HiPerFect Transfection Reagent (Qiagen). All experiments were performed in quadruplicate, and normalised cell index values were calculated according to the manufacturer's instructions.

In vivo assay in PDX. The $\mathrm{HBCx}-60$ TNBC PDX was directly established from a metaplastic TNBC and was routinely passaged by subcutaneous engraftment into the interscapular fat pad in Crl:NU(Ico)-Foxn1nu nude mice (Charles River Laboratories, Wilmington, MA, USA), with protocol and animal housing in accordance with national regulations and international guidelines (Marangoni et al, 2007). Female 8-week-old mice with 60$200 \mathrm{~mm}^{3}$ tumours were randomly assigned to the control or treated groups. Mice (at least 7 per group) were treated with $100 \mu \mathrm{l}$ of $200 \mu \mathrm{M}$ of IWR-1 (IO161, Sigma, St Louis, MO, USA) diluted in PBS by subcutaneous injection, 4 times per week, as previously described (Rognoni et al, 2014). Tumour growth was evaluated measuring two perpendicular tumour diameters with a caliper twice a week. Individual tumour volumes were calculated: $\mathrm{V}=$ $a \times b^{2} / 2$, where $a$ is the largest diameter and $b$ is the smallest diameter. For each tumour, volumes were expressed in relation to the initial volume as relative tumour volume (RTV).

Statistical analysis. Relationships between RSPO or LGR expression and clinical, histological, and laboratory parameters were estimated with Chi-square and Mann-Whitney tests. Metastasisfree survival (MFS) was determined as the interval between diagnosis and detection of the first metastasis. Survival distributions were estimated with the Kaplan-Meier method, and the significance of differences between survival rates was ascertained with the log-rank test. The Cox proportional hazards regression model was used to assess prognostic significance and the results are expressed as hazard ratios and 95\% confidence intervals. Hierarchical clustering was performed with the GeneANOVA software (Didier et al, 2002).

\section{RESULTS}

Expression of RSPOs and LGRs in BC tumours, TNBC subtype, and $\mathrm{BC}$ cell lines. Pending the development of a reliable RSPO antibody (we tested three different commercial antibodies), the best way to study RSPO expression consists of mRNA assay. The difficulty of detecting the RSPO proteins by western blotting is a well-known problem in the literature (Seshagiri et al, 2012; Chartier et al, 2016). We first examined RSPO mRNA expression in a series of 446 breast tumours, including 68 TNBC. Overexpression of at least one $R S P O$ gene was observed in $11.6 \%$ of $\mathrm{BC}$ and $55.8 \%$ of TNBC, mainly involving the RSPO4 gene $(9.2 \%$ in the total population of $\mathrm{BC}$ and $42.6 \%$ in TNBC) and RSPO2 gene $(2.7 \%$ in the total population of $\mathrm{BC}$ and $17.6 \%$ in TNBC; Table 1). In contrast, RSPO1 and RSPO3 were rarely overexpressed in BC (only $1.1 \%$ and $0.2 \%$, respectively; Table 1 ). None of the 446 tumours overexpressed all $R S P O$ at the same time. Interestingly, four TNBCs of our cohort were MBCs and all overexpressed at least one $R S P O$ (one sample overexpressed RSPO2, two samples overexpressed $\mathrm{RSPO} 4$ and one overexpressed $\mathrm{RSPO} 2$ and $\mathrm{RSPO} 4$. To validate the very high prevalence of $R S P O$ overexpression in $\mathrm{MBC}$, we examined $R S P O$ overexpression in a second cohort of $28 \mathrm{MBC}$. This study confirmed that RSPO2 was more often overexpressed in this specific subtype than in TNBC (46\% vs $17.6 \%$; Table 1).

Among the 32 BC cell lines, 9 (28\%) overexpressed at least one gene of the RSPO family with a majority of TNBC cell lines (7 out of 16: 43.7\%; Table 1 and Supplementary Table S2) as observed for the tumour sample cohort.

We also verified the expression of the RSPO receptors, LGR4, LGR5 and LGR6, in our series of 446 breast tumours and found that the majority of tumours expressed LGR4 (median Ct of 27.43) and, to a lesser extent, LGR5 and LGR6 (median Ct of 36.4 and 31.92, respectively; data not shown). Distributions of $R S P O$ receptor expression are detailed in Table 1 and Supplementary Table S2 for breast tumours and cell lines, respectively.

Mechanisms underlying RSPO overexpression in BC. It has been observed that RSPO2 and RSPO3 overexpression in CRC is at least partly due to the presence of fusion transcripts (EIF3E (exon1)-RSPO2 (exon2), PTPRK (exon1)-RSPO3 (exon2), and $P T P R K$ (exon7)-RSPO3 (exon2); Seshagiri et al, 2012). In order to explain cases of RSPO2 and RSPO3 overexpression in BC cells,

Table 1. Overexpression of RSPO and LGR in BC tumours and BC cell lines

\begin{tabular}{|c|c|c|c|c|c|c|c|c|c|}
\hline Overexpression & $\begin{array}{c}\text { RSPO1, } \\
\text { n (\%) }\end{array}$ & $\begin{array}{c}\text { RSPO2, } \\
\text { n (\%) }\end{array}$ & $\begin{array}{c}\text { RSPO3, } \\
\text { n (\%) }\end{array}$ & $\begin{array}{c}\text { RSPO4, } \\
n(\%)\end{array}$ & $\begin{array}{c}\text { All }{ }^{a} \text { RSPO, } \\
n(\%)\end{array}$ & $\begin{array}{l}\text { LGR4, } \\
\text { n (\%) }\end{array}$ & $\begin{array}{l}\text { LGR5, } \\
\text { n (\%) }\end{array}$ & $\begin{array}{c}\text { LGR6, } \\
n(\%)\end{array}$ & $\begin{array}{c}\text { All }{ }^{a} \text { LGR, } \\
n(\%)\end{array}$ \\
\hline \multicolumn{10}{|l|}{ Patient tumour samples } \\
\hline Whole population $(n=446)$ & $5(1.1 \%)$ & $12(2.7 \%)$ & $1(0.2 \%)$ & $41(9.2 \%)$ & 52 (11.6\%) & $3(0.6 \%)$ & $16(3.6 \%)$ & $4(0.9 \%)$ & $23(5.1 \%)$ \\
\hline Metaplastic cohort $(n=28)$ & $0(0 \%)$ & $13(46 \%)$ & $0(0 \%)$ & $12(42.8 \%)$ & $18(64 \%)$ & $0(0 \%)$ & 9 (32.1\%) & $0(0 \%)$ & 9 (32.1\%) \\
\hline \multicolumn{10}{|l|}{ Cancer cell lines } \\
\hline Whole population $(n=32)$ & $2(6.2 \%)$ & $2(6.2 \%)$ & $4(12.5 \%)$ & $4(12.5 \%)$ & $9(28 \%)$ & $4(12.5 \%)$ & $2(6.2 \%)$ & $9(28 \%)$ & $14(43.8 \%)$ \\
\hline
\end{tabular}


we therefore first looked for the presence for these fusion transcripts by qRT-PCR using specific primers (Supplementary Table S3). We identified fusion transcripts involving RSPO2 only in two TNBC cell lines: HBCc-15 and BT549, and in HBCX-15 TNBC PDX from which the HBCc-15 cell line was established (Figure 1A). The two different fusion transcripts EIF3E (exon1)RSPO2 (exon2) and EIF3E (exon1)-RSPO2 (exon3) were found in both the HBCx-15 PDX and the derived HBCc-15 cell line (Figure 1A, left panel), and fusion transcript EIF3E (exon1)RSPO2 (exon3) was found in the BT549 cell line (Figure 1A, right panel). The HBCc-15 and BT549 cell lines and the HBCx-15 PDX expressed the highest levels of RSPO2 transcripts (Supplementary Table S2 and data not shown).

We confirmed RSPO2 expression by IHC in the HBCx-15 TNBC PDX, strongly suggesting that the fusion transcripts detected in this PDX are functional (Figure 1B).

We did not detect any fusion transcript involving RSPO2 or RSPO3 in our series of 446 breast tumours.

The presence of fusion transcripts therefore cannot explain the majority of the RSPO overexpression observed in BC. On the basis of TCGA data (http://www.cbioportal.org/, breast invasive carcinoma, TCGA provisional), another mechanism can be proposed, such as amplification or hypomethylation of RSPO genes, as, in the TCGA population, RSPO2 expression was correlated with $R S P O 2$ gene amplification $\left(P=8 \times 10^{-5}\right.$ for the total population and $P=3 \times 10^{-3}$ for the TN subtype) and RSPO4 expression was significantly correlated with $R S P O 4$ gene hypomethylation $(P=1.7$ $\times 10^{-6}$ for the total population and $P=8.2 \times 10^{-4}$ for the TN subtype; Supplementary Figure S2).
Relationship between RSPO and LGR gene mRNA levels and clinical parameters. $\mathrm{RSPO} 2$ and $\mathrm{RSPO} 4$ overexpression levels were associated with high SBR histological grade $\left(P=5.5 \times 10^{-3}\right.$ and $P=2.4 \times 10^{-3}$, respectively), negative hormonal receptor status $\left(P<10^{-7}\right.$ for ER and $P=4.6 \times 10^{-5}$ for $\mathrm{PR}$ and $P<10^{-7}$ for ER and $P=2.6 \times 10^{-7}$ for $\mathrm{PR}$, respectively), elevated Ki67 mRNA $\left(P=2.7 \times 10^{-2}\right.$ and $P=1.7 \times 10^{-7}$, respectively), and TNBC subtype $\left(P<10^{-7}\right.$ and $P=2.1 \times 10^{-7}$, respectively) (Supplementary Tables S4 and S5). Results for LGR5 are detailed in Supplementary Table S6. These correlation tests cannot be performed for tumours overexpressing RSPO1, RSPO3 and LGR4 and LGR6 owing to the small number of overexpressing samples.

These findings indicate that RSPO2 and RSPO4 overexpression levels are associated with aggressive characteristics of BC.

Relationship between RSPO gene mRNA level and MFS. A logrank test was used to identify relationships between MFS and RSPO2 and RSPO4 mRNA levels. Patients with BC (Figure 2A) or TNBC (Figure $2 \mathrm{~B}$ ) overexpressing $R S P O 2$ had significantly poorer MFS $\left(P=3.6 \times 10^{-4}\right.$ and $P=4.4 \times 10^{-2}$, respectively $)$. The prognostic significance of the parameters identified in univariate analysis (including histopathological grade, lymph node status, macroscopic tumour size, PR status; Supplementary Table S1) and RSPO2 expression status persisted (except for histopathological grade and PR status) in Cox multivariate regression analysis of MFS (Supplementary Table S7). These associations were not observed for RSPO4 (data not shown).

LGR5 overexpression was not associated with MFS in the BC population or the TNBC subpopulation (data not shown). Survival

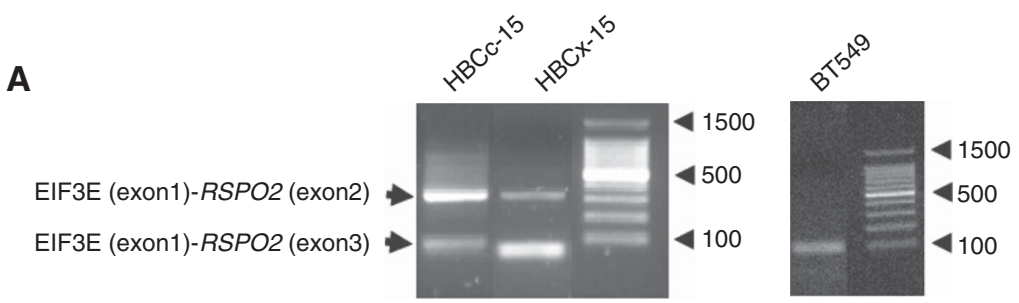

B

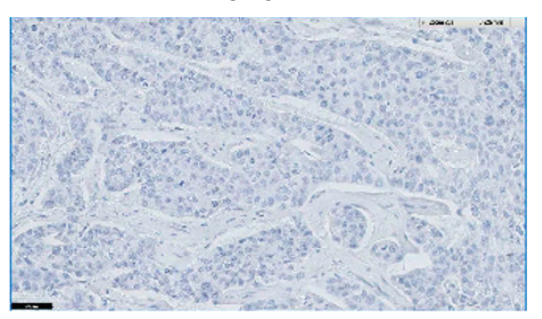

$50 \mu \mathrm{m}$

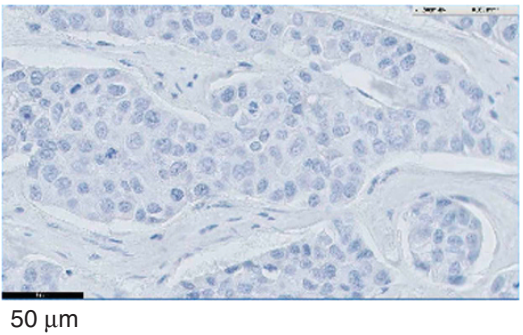

HBCx-15

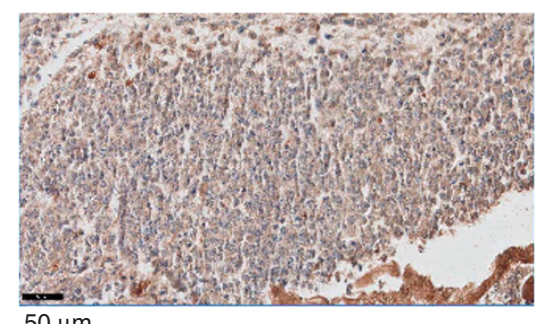

$50 \mu \mathrm{m}$

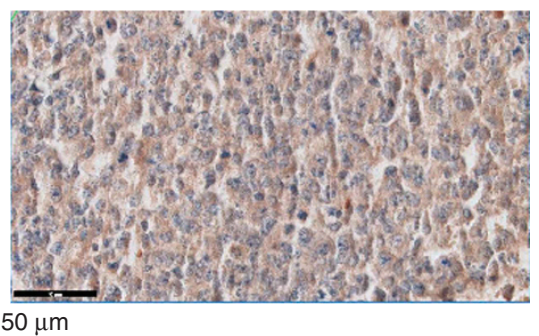

Figure 1. Presence of functional RSPO fusion transcripts in BC cells. (A) Detection of EIF3E (exon1)-RSPO2 (exon2) and EIF3E (exon1)-RSPO2 (exon3) fusion transcripts (351 pb and 88 pb, respectively, see Supplementary Table S3) in HBCx-15 TNBC PDX and its derived HBCc-15 cell line and BT549 cell line. (B) Detection of RSPO2 protein in HBCx-15 TNBC PDX and HBCx-3 (negative control, TNBC PDX, which does not express RSPO2). HBCx-3 TNBC PDX (left panel) and HBCx-15 TNBC PDX (right panel) blocks were prepared and immunostained with anti-RSPO2 antibody. Magnification $\times 20$ (top panels) and $\times 40$ (bottom panels). 

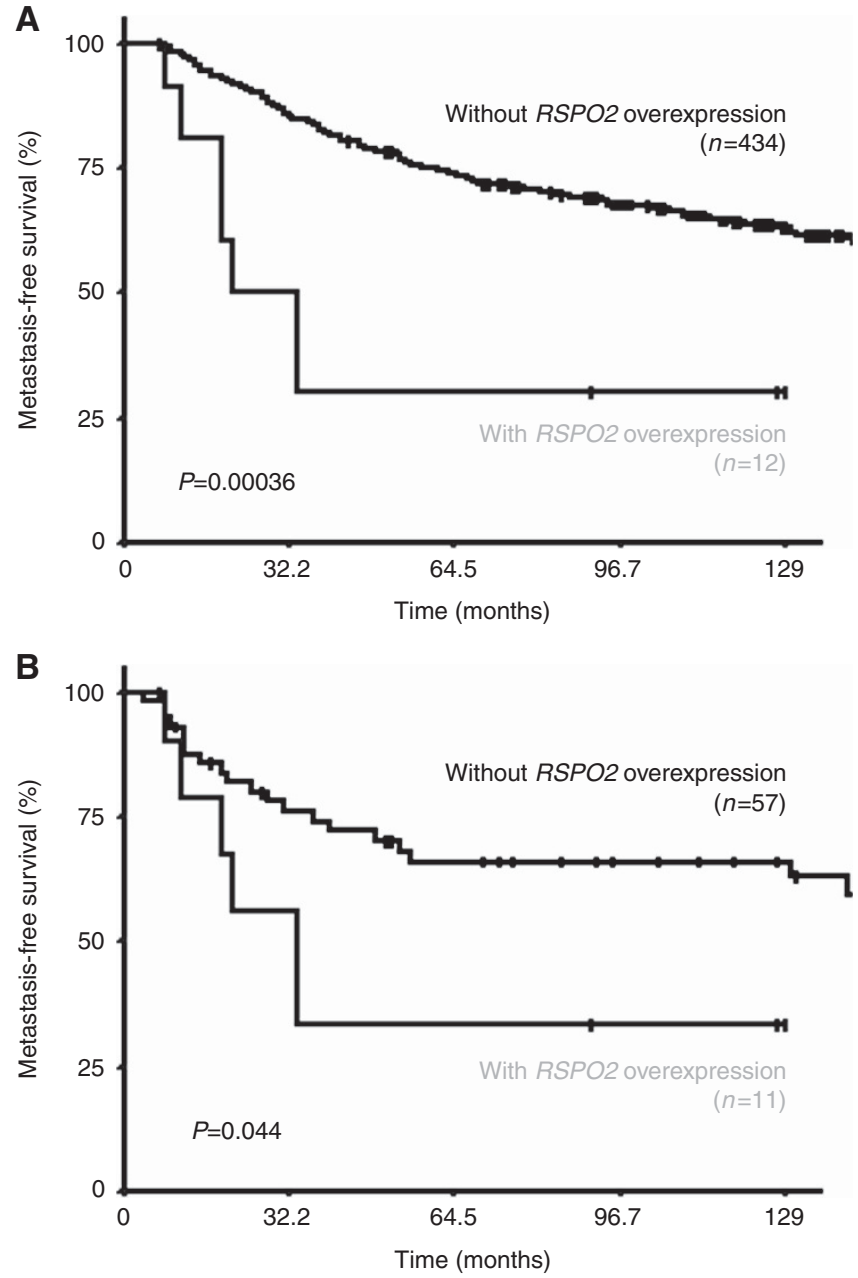

Figure 2. Relationship between RSPO2 gene mRNA level and MFS in BC. (A) MFS curves for patients with RSPO2 overexpression in the total population. (B) MFS curves for patients with RSPO2 overexpression in patients with TNBC.

analysis cannot be performed for patients with tumours overexpressing RSPO1, RSPO3, LGR4, or LGR6 because of the very small sample sizes.

Altogether, our results raise the hypothesis that RSPO overexpression, particularly $\mathrm{RSPO} 2$ overexpression, may have an important role in the development of TNBC and MBC.

Correlation between expression of RSPO and LGR genes and genes involved in various cancer pathways. The TNBC subgroup is characterised by EMT, stem cell traits, and a high level of Wnt $\beta$ catenin pathway activity (Sarrio et al, 2008; King et al, 2012). In order to further investigate our hypothesis, we therefore studied the correlations between the levels of expression of RSPO and their $L G R$ receptors and EMT markers (CDH1, VIM, ZEB1, ZEB2, SNAIL, SNAIL2, TWIST1), stem cell markers (ALDHA1A1, $A L D H A 1 A 3, C D 133)$, and $\mathrm{Wnt} / \beta$-catenin activity (AXIN2, $D K K 1, T C F 4, L E F 1, M M P 7)$ in TNBC. By hierarchical clustering of the samples, the $7 R S P O / L G R$ gene expression signature dichotomised the 68 TNBC analysed into two subgroups: a high $R S P O / L G R$ expression group $(n=44)$ and a low $R S P O / L G R$ expression group $(n=24)$. Mann-Whitney test demonstrated positive correlations between RSPO/LGR expression levels and EMT markers $\left(P=4.5 \times 10^{-2}\right.$ for VIM and $P=4.7 \times 10^{-3}$ for TWIST1), stem cell markers $\left(P=4.5 \times 10^{-3}\right.$ for $C D 133$ and $P=1.6 \times 10^{-2}$ for ALDHA1A1), and $\mathrm{Wnt} / \beta$-catenin pathway activity $\left(P=4.8 \times 10^{-2}\right.$ for $A X I N 2$ and $P=2.4 \times 10^{-2}$ for MMP7)
Table 2. Relationships between RSPO/LGR gene expression and gene expression levels of different pathways of carcinogenesis

\begin{tabular}{|c|c|c|c|}
\hline Genes & $\begin{array}{l}\text { TNBC with high } \\
\text { level of RSPO-LGR } \\
\text { mRNA expression } \\
\quad(n=44)\end{array}$ & $\begin{array}{l}\text { TNBC with low } \\
\text { level of RSPO-LGR } \\
\text { mRNA expression } \\
(n=24)\end{array}$ & $P^{a}$ \\
\hline \multicolumn{4}{|c|}{ Stem cell pathway } \\
\hline CD133 & $1.1(0.02-7.9)$ & $0.2(0.006-5.8)$ & 0.0045 \\
\hline ALDHA1A3 & $0.6(0.1-11)$ & $0.4(0.08-14.2)$ & 0.37 \\
\hline ALDHA1A1 & $0.1(0.02-0.7)$ & $0.09(0.1-0.6)$ & 0.016 \\
\hline \multicolumn{4}{|c|}{ EMT pathway } \\
\hline $\mathrm{CDH} 1$ & $0.6(0.01-3)$ & $0.7(0.047-5.4)$ & 0.13 \\
\hline VIM & $0.4(0.15-2.1)$ & $0.3(0.02-0.8)$ & 0.045 \\
\hline ZEB1 & $0.3(0-1.2)$ & $0.3(0-0.8)$ & 0.77 \\
\hline ZEB2 & $0.4(0-1.9)$ & $0.3(0-0.9)$ & 0.2 \\
\hline SNAIL & $1.7(0-8.2)$ & $1.2(0-13.1)$ & 0.54 \\
\hline SNAIL2 & $0.6(0-11.4)$ & $0.5(0-3.8)$ & 0.054 \\
\hline TWIST1 & $0.4(0.05-3.8)$ & $0.2(0.04-1)$ & 0.0047 \\
\hline \multicolumn{4}{|c|}{ WNT/ $\beta$-catenin pathway } \\
\hline AXIN2 & $0.35(0.07-3.6)$ & $0.2(0.04-1.3)$ & 0.048 \\
\hline DKK1 & $5.5(0-786)$ & $8.8(2.6-358)$ & 0.97 \\
\hline TCF4 & $0.8(0-3.6)$ & $0.6(0-3)$ & 0.082 \\
\hline LEF1 & $0.3(0-1.8)$ & $0.2(0.02-0.6)$ & 0.32 \\
\hline MMP7 & $3.5(0-58)$ & $0.8(0.02-19)$ & 0.024 \\
\hline \multicolumn{4}{|c|}{$\begin{array}{l}\text { Abbreviations: } E M T=\text { epithelial-mesenchymal transition; } L G R=\text { leucine-rich repeat contain- } \\
\text { ing } G \text { protein-coupled receptor; } T N B C=\text { triple-negtive breast cancer. } \\
{ }^{{ }} \text {Mann-Whitney test. }\end{array}$} \\
\hline
\end{tabular}

(Table 2). RSPO overexpression may therefore have a role in TNBC carcinogenesis via activation of various pathways, such as the Wnt/ $\beta$-catenin pathway.

RSPO2 and RSPO4 stimulate the Wnt/ $\beta$-catenin pathway in human TNBC cell lines. To determine whether RSPO2 and/or RSPO4 overexpression (the two RSPO genes most frequently overexpressed in $\mathrm{BC}$ ) may stimulate the activity of the $\mathrm{Wnt} / \beta$ catenin pathway in BC cells, we assessed the effect of RSPO2-, RSPO4-, and Wnt3a-conditioned media on the expression of active $\beta$-catenin and phosphorylated-LRP6 (phospho-LRP6), two wellknown markers of $\mathrm{Wnt} / \beta$-catenin activity, by western blotting in the MDA-MB-468 TNBC cell line, which does not express any RSPO. RSPO2 and RSPO4 strongly enhanced the effect of Wnt3a on phospho-LRP6 levels and, to a lesser extent, active $\beta$-catenin (Figure 3A). Similar results were obtained with a second TNBC breast cell line, MDA-MB-231 (Supplementary Figure S3).

We then performed luciferase assays using TOPflash containing six TCF-binding elements as reported plasmid and found that RSPO 2 and RSPO4 stimulated Wnt $/ \beta$-catenin activity and potentiated the effect of Wnt3a on this signalling pathway in MDA-MB-468 cells (Figure 3B).

We also found that RSPO2 and RSPO4 strongly enhanced the positive effect of $\mathrm{Wnt} 3 \mathrm{a}$ on the levels of two $\mathrm{Wnt} / \beta$-catenin pathway target genes, AXIN2 and DKK1, in the MDA-MB-468 cell line (Figure 3C).

Altogether, our results strongly suggest that $R S P O$ overexpression, particularly RSPO2 overexpression observed in $\mathrm{BC}$, enhances breast carcinogenesis by activating the $\mathrm{Wnt} / \beta$-catenin pathway.

Inhibition of RSPO2 expression inhibits proliferation of the BT549 TN breast cell line. Our previous findings suggested that inhibition of the biological function of RSPO2 in $\mathrm{BC}$ cells would inhibit their proliferation. To examine this hypothesis, we first determined the effect of inhibition of RSPO2 expression by using the siRNA approach on proliferation of the BT549 TN breast cell line, selected for its high level of RSPO2 expression. As expected, effective inhibition of endogenous $\mathrm{RSPO} 2$ expression by two different $R S P O 2$-specific siRNA resulted in statistically significant 

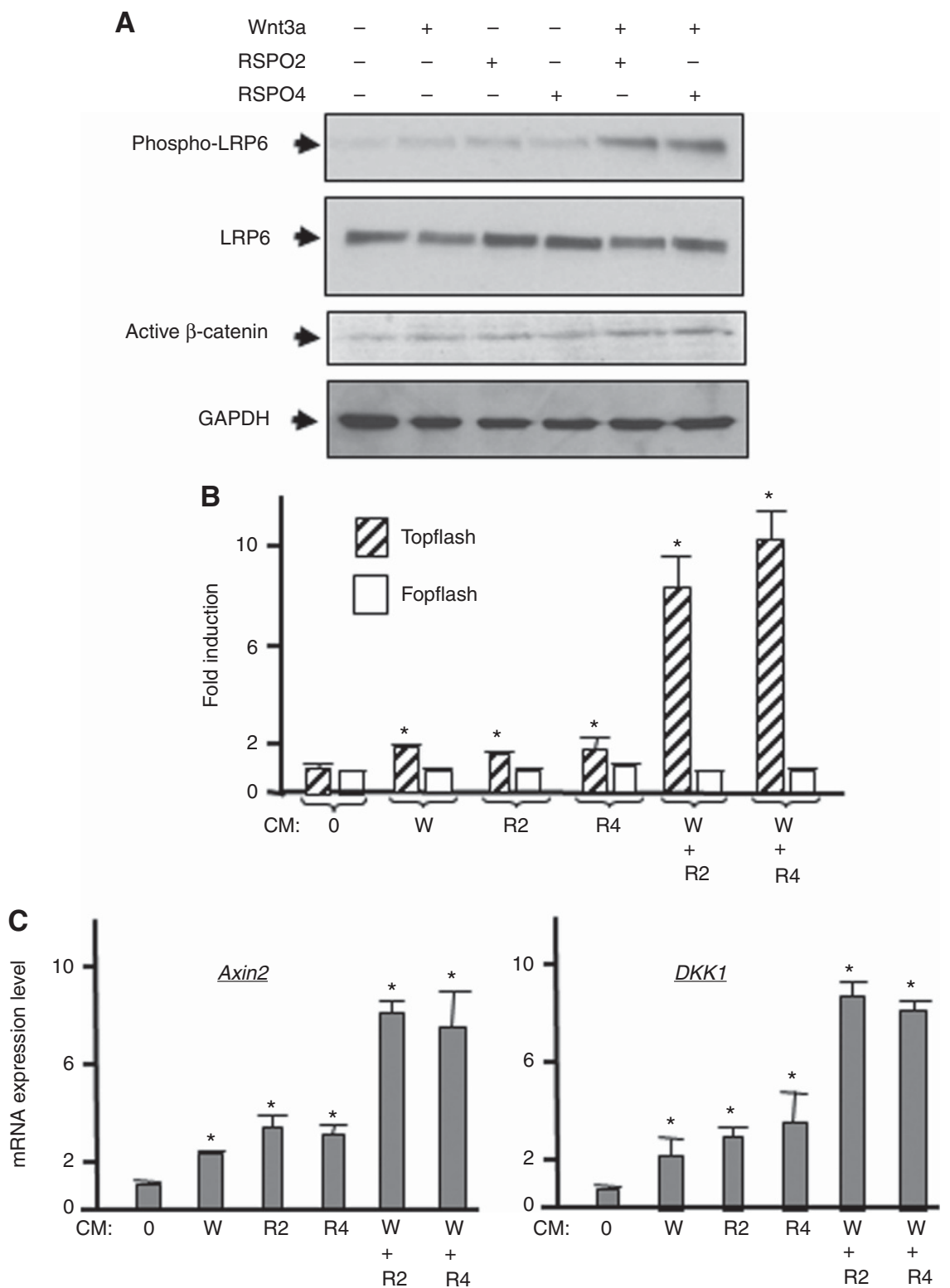

Figure 3. RSPO2 and RSPO4 stimulate Wnt/ $\beta$-catenin pathway activity in MDA-MB-468 cells. (A) Effect of RSPO2, RSPO4 and/or Wnt3a on the expression of phosphorylated LRP (phospho-LRP) and active $\beta$-catenin. (B) Effect of RSPO2, RSPO4, and/or Wnt3a on Wnt/ $\beta$-catenin transcriptional activity. (C) Effect of RSPO2, RSPO4, and/or Wnt3a on the expression of Axin2 and DKK1. CM: conditioning medium, W: Wnt3a, R2: RSPO2, R4: $R S P O 4$, *: indicates $P \leqslant 0.05$ vs control (CM: 0$)$.

inhibition of BT549 cell proliferation $(P<0.001$, Mann-Whitney test; Figure 4).

The Wnt/ß-catenin inhibitor, IWR-1, inhibits the growth of a human TNBC PDX overexpressing RSPO2. We then tested the effect of the $\mathrm{Wnt} / \beta$-catenin pathway inhibitor, IWR-1, on the growth of a human TNBC PDX (HBCx-60) overexpressing RSPO2 $(\mathrm{Ct}=27.94)$. This PDX displays a metaplastic phenotype. Treatment by IWR-1 resulted in significant tumour growth inhibition and this effect persisted after 2 weeks (Figure 4C). Optimal tumour growth inhibition (TGI) of treated tumours vs controls was calculated as the ratio of the mean RTV in the treated group to the mean RTV in the control group at the same time. Treatment by IWR-1 resulted in a TGI of $23 \%$. Untreated xenografts rapidly reached the ethical size limit within 12 days and mice had to be killed.

Inhibition of $\mathrm{Wnt} / \beta$-catenin pathway activity in this RSPO2overexpressing breast tumour therefore induces tumour growth inhibition.

\section{DISCUSSION}

This study of a series of breast tumours showed, for the first time, that the RSPO gene family is overexpressed in $11.6 \%$ of tumours, mainly in TNBC (55.8\%) and MBC (64\%). This overexpression mainly concerns RSPO2 (2.7\% in BC, $17.6 \%$ in TNBC, and $46.4 \%$ in MBC) and RSPO4 (9.2\% in BC, $42.6 \%$ in TNBC, and $42.8 \%$ in $\mathrm{MBC})$. These observations led us to assume that overexpression of certain RSPOs could confer an advantage for the development of the breast tumour.

Various studies have shown that RSPO2 and RSPO3 overexpression is due to the presence of gene fusions involving RSPO, EIF3E, and PTPRK genes in CRC and in malignant peripheral nerve sheath tumours (Seshagiri et al, 2012; Watson et al, 2013; Shinmura et al, 2014). Other studies have indicated that other mechanisms may also be involved in RSPO overexpression in cancers (Robinson et al, 2015; Gong et al, 2014). In our study, only 

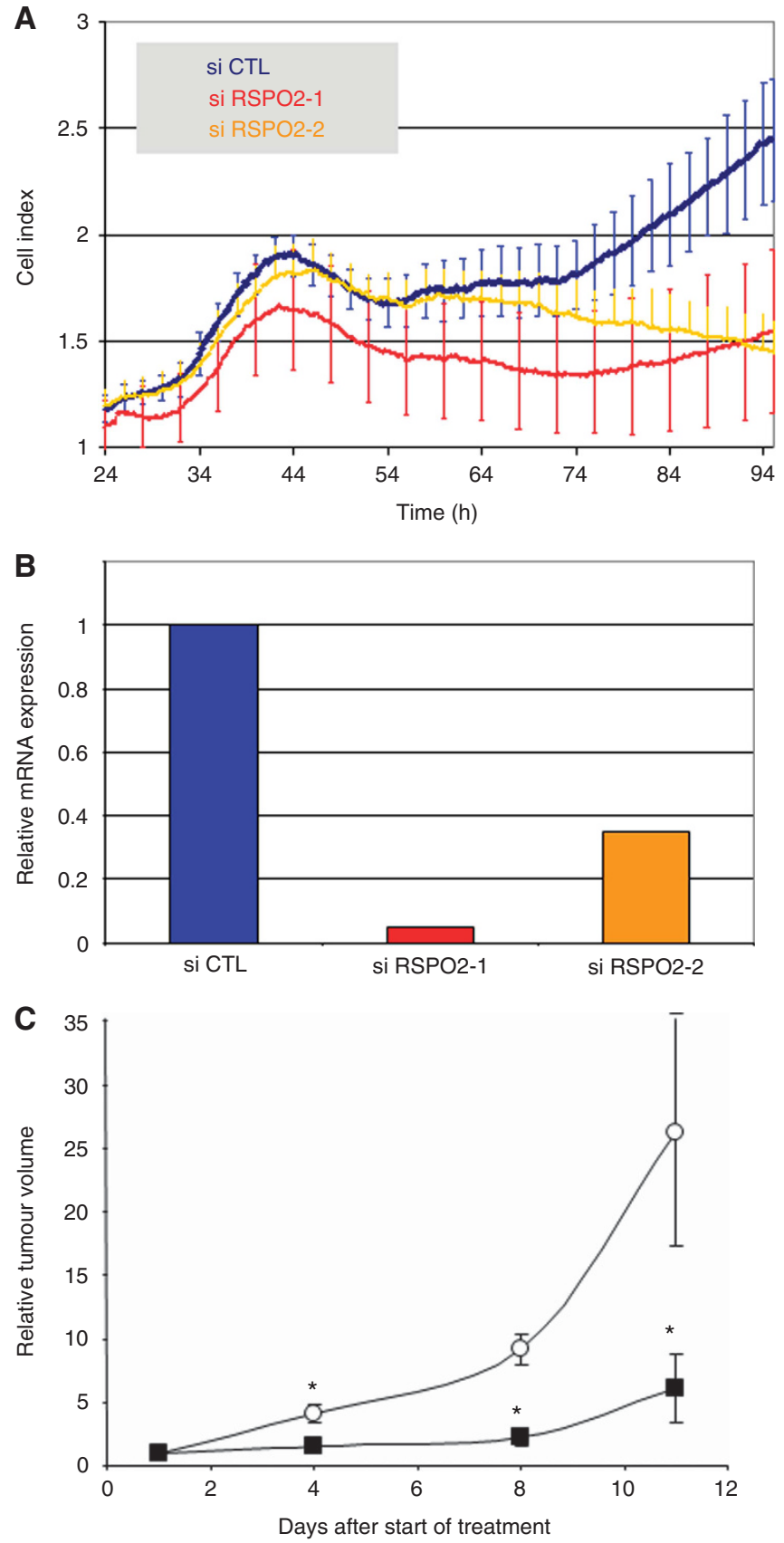

Figure 4. Effect of inhibition of RSPO2. (A) Inhibition of proliferation of BT549 cells by two siRNA of RSPO2. (B) Inhibition of mRNA expression determined by qRT-PCR: RSPO2 expression was decreased by siRSPO2-1 and siRSPO2-2 to $5 \%$ and $35 \%$, respectively, vs CTL (control). ${ }^{\star} P<0,0001$, Mann-Whitney test. (C) The Wnt/ $\beta$-catenin inhibitor IWR-1 inhibits the growth of HBCx-60 RSPO2-overexpressing human TNBC PDX; $\mathbf{\square}=$ IWR-1, $\bigcirc=$ vehicle alone. Tumour growth was evaluated by plotting the mean RTV \pm s.d. per group over time after first treatment. ${ }^{*} P<0.05$, unpaired $t$-test.

one case of RSPO2 overexpression in BC (in the HBCx-15 TNBC PDX and the derived HBCc-15 cell line) can be explained by the presence of fusion transcripts involving EIF3E but not PTPRK. The small number of fusion transcripts indicates that other mechanisms are also involved in RSPO overexpression in BC. RSPO2 is located on $8 \mathrm{q} 23$ near the $c-M Y C$ gene (8q24). $c-M Y C$ amplification is observed in many different cancers, particularly in $16 \%$ of cases of BC (TCGA, Cancer Genome Atlas Network, 2012). We observed a correlation between $\mathrm{RSPO} 2$ expression and amplification of this region in BC (TCGA data, http://www.cbioportal.org/), suggesting that $R S P O 2$ overexpression in $\mathrm{BC}$ could be at least partly due to co-amplification with $M Y C$. In this context, it is noteworthy that $M Y C$ and PVT1 synergise to increase the level of RSPO1 in BC (Sarver et al, 2016). RSPO overexpression could also be due to hypomethylation. Although carcinogenesis involves various pathways of gene alterations driven by DNA methylation, several studies have implicated activation of gene expression via hypomethylation. Global genomic hypomethylation is found in many types of cancer, particularly in BC, and is associated with high metastatic risk and death (Cheishvili et al, 2015). We observed a correlation between RSPO4 expression and RSPO4 hypomethylation in BC (TCGA data, http://www.cbioportal.org/). This mechanism could therefore be responsible for RSPO4 overexpression in BC.

Patients with $R S P O 2$-overexpressing TNBC have significantly poorer MFS than patients with TNBC not overexpressing this $R S P O$. It is not the case for RSPO4. Futhermore, the inhibition of RSPO2 expression in the BT549 TN cell line inhibits cell growth. These findings strongly suggest that RSPO overexpression, particularly $R S P O 2$ overexpression, has an important role in the development of TNBC. These results suggest that overexpression of RSPO2 has specific effects on the development of breast tumours. The hypothesis that RSPO2 has specific function is supported by the fact that deficiency for RSPO2 in mice is postnatally lethal, indicating that this RSPO protein has functions that are non-redundant from the other RSPO members (Nam et al, 2007).

The role of RSPO in breast carcinogenesis is supported by the fact that $R S P O 2$ and $R S P O 3$ are overexpressed by mouse mammary tumour virus proviral insertions in mouse mammary tumours and that RSPO2 overexpression in mammary cell lines stimulates tumour growth (Callahan et al, 2012; Klauzinska et al, 2012). RSPO overexpression has also been found in CRC, pancreatic ductal adenocarcinoma, lung adenocarcinomas, prostate cancer, and malignant peripheral nerve sheath tumours, suggesting a crucial role of RSPO in the development of various cancers (Seshagiri et al, 2012; Watson et al, 2013; Gong et al, 2014; Shinmura et al, 2014; Ilmer et al, 2015; Robinson et al, 2015).

Many experimental arguments and observations strongly suggest that the abnormally high activity of the $\mathrm{Wnt} / \beta$-catenin pathway has a crucial role in the development of $\mathrm{BC}$, specifically in TNBC, by stimulating EMT and stem cell growth (Lin et al, 2000; Li et al, 2003; Lindvall et al, 2006; Yook et al, 2006; Lehmann et al, 2011; Xu et al, 2012; Dey et al, 2013). Furthermore, constitutive activation of the $\mathrm{Wnt} / \beta$-catenin pathway induces mammary metaplastic carcinomas in mice (Teuliere et al, 2005). However, the molecular mechanisms responsible for activation of the $\mathrm{Wnt} / \beta$-catenin signalling pathway in $\mathrm{BC}$ have not been elucidated (Howe and Brown, 2004). Several reports suggest that hyperactivity of the $\mathrm{Wnt} / \beta$-catenin pathway in this cancer could be due to aberrant expression levels of $L R P 6 / 5$, FZD7, Wnt ligands, and Wnt inhibitors (King et al, 2012). The $A P C$ and CTNNB1 mutations inducing $\beta$-catenin stabilisation observed in various type of cancer, such as CRC, are rare in BC. Our data raise the interesting hypothesis that $R S P O 2 / 4$ overexpression could be one of the mechanisms responsible for activation of the $\mathrm{Wnt} / \beta$-catenin pathway, thereby activating breast carcinogenesis. First, we found that the RSPO gene family is mainly overexpressed in TNBC. Second, a positive correlation was observed between $R S P O / L G R$ expression and EMT markers, stem cell markers, and $\mathrm{Wnt} / \beta$-catenin pathway activity in TNBC. Third, we demonstrated that $\mathrm{RSPO} 2$ and $\mathrm{RSPO} 4$ stimulate the activity of this signalling pathway in two different TN breast cell lines. Fourth, inhibition of the growth of the HBCx-60 RSPO2overexpressing metaplastic TNBC PDX by IWR-1 strongly suggests that the positive effect of $\mathrm{RSPO} 2$ on breast tumour 
growth is dependent on its ability to stimulate the activity of the Wnt $/ \beta$-catenin pathway. Our hypothesis that RSPO overexpression could stimulate breast carcinogenesis by inducing Wnt/ $\beta$ catenin pathway activity is strongly supported by recent studies showing that inhibition of RSPO by specific antibodies attenuates $\beta$-catenin signalling and tumorigenesis in multiple cancer types (ovarian cancer for RSPO1, colon and pancreatic cancer for $R S P O 2$, non-small lung cancer, colorectal and ovarian cancer for RSPO3; Chartier et al, 2016).

\section{CONCLUSION}

Despite considerable progress in cancer research, the mortality rates of TNBC and MBC have remained unchanged over the past decade primarily due to the failure to identify specific targets. Responses to systemic chemotherapy, particularly for $\mathrm{MBC}$, are suboptimal compared with patients with standard invasive ductal carcinoma and limited data are available concerning the optimal treatment modalities (Aydiner et al, 2015). Our study supports the identification of RSPO overexpression as a new therapeutic target and an attractive predictive biomarker for the development of therapies targeting the $\mathrm{Wnt} / \beta$-catenin signalling pathway, particularly in TNBC and the metaplastic subtype.

\section{ACKNOWLEDGEMENTS}

We thank Dr Shinji Takada for donating mouse fibroblast L cells producing Wnt-3a and L cells stably transfected with the pGKneo plasmid. This work was supported by a medicalscientific grant from the Fondation pour la Recherche Médicale (DEA20130727212; to CF), by the Agence Nationale de la Recherche (Programme Investissements d'Avenir-Institut Carnot ANR-11CARN-008-01), and GEFLUC, Les Entreprises contre le Cancer (Grant 2014 59/188). This work was also supported by the Ligue Nationale de lutte Contre le Cancer and the Cancéropôle Ilede-France. We thank the staff of Institut Curie-René Huguenin Hospital for their assistance in specimen collection and patient care and the in vivo Experiment Platform-Institut Curie managed by Isabelle Grandjean.

\section{CONFLICT OF INTEREST}

The authors declare no conflict of interest.

\section{REFERENCES}

Aydiner A, Sen F, Tambas M, Ciftci R, Eralp Y, Saip P, Karanlik H, Fayda M, Kucucuk S, Onder S, Yavuz E, Muslumanoglu M, Igci A (2015) A metaplastic breast carcinoma versus triple-negative breast cancer: survival and response to treatment. Medicine (Baltimore) 94: e2341.

Behrens J, Lustig B (2004) The Wnt connection to tumorigenesis. Int J Dev Biol 48: 477-487.

Bieche I, Nogues C, Lidereau R (1999) Overexpression of BRCA2 gene in sporadic breast tumours. Oncogene 18: 5232-5238.

Bieche I, Onody P, Tozlu S, Driouch K, Vidaud M, Lidereau R (2003) Prognostic value of ERBB family mRNA expression in breast carcinomas. Int J Cancer 106: 758-765.

Bieche I, Parfait B, Le Doussal V, Olivi M, Rio MC, Lidereau R, Vidaud M (2001) Identification of CGA as a novel estrogen receptor-responsive gene in breast cancer: an outstanding candidate marker to predict the response to endocrine therapy. Cancer Res 61: 1652-1658.

Bienz M, Clevers H (2000) Linking colorectal cancer to Wnt signaling. Cell 103: $311-320$
Bilir B, Kucuk O, Moreno CS (2013) Wnt signaling blockage inhibits cell proliferation and migration, and induces apoptosis in triple-negative breast cancer cells. J Transl Med 11: 280.

Cai J, Guan H, Fang L, Yang Y, Zhu X, Yuan J, Wu J, Li M (2013) MicroRNA374a activates Wnt/beta-catenin signaling to promote breast cancer metastasis. J Clin Invest 123: 566-579.

Callahan R, Mudunur U, Bargo S, Raafat A, McCurdy D, Boulanger C, Lowther W, Stephens R, Luke BT, Stewart C, Wu X, Munroe D, Smith GH (2012) Genes affected by mouse mammary tumor virus (MMTV) proviral insertions in mouse mammary tumors are deregulated or mutated in primary human mammary tumors. Oncotarget 3: 1320-1334.

Cancer Genome Atlas Network. Comprehensive molecular portraits of human breast tumours (2012) Nature 490: 61-70.

Cerami E, Gao J, Dogrusoz U, Gross BE, Sumer SO, Aksoy BA, Jacobsen A, Byrne CJ, Heuer ML, Larsson E, Antipin Y, Reva B, Goldberg AP, Sander C, Schultz N (2012) The cBio cancer genomics portal: an open platform for exploring multidimensional cancer genomics data. Cancer Discov 2: 401-404.

Chartier C, Raval J, Axelrod F, Bond C, Cain J, Dee-Hoskins C, Ma S, Fischer MM, Shah J, Wei J, Ji M, Lam A, Stroud M, Yen WC, Yeung P, Cancilla B, O’Young G, Wang M, Kapoun AM, Lewicki J, Hoey T, Gurney A (2016) Therapeutic targeting of tumor-derived R-spondin attenuates beta-catenin signaling and tumorigenesis in multiple cancer types. Cancer Res 76: 713-723.

Cheishvili D, Stefanska B, Yi C, Li CC, Yu P, Arakelian A, Tanvir I, Khan HA, Rabbani S, Szyf M (2015) A common promoter hypomethylation signature in invasive breast, liver and prostate cancer cell lines reveals novel targets involved in cancer invasiveness. Oncotarget 6: 33253-33268.

Dey N, Young B, Abramovitz M, Bouzyk M, Barwick B, De P, Leyland-Jones B (2013) Differential activation of Wnt-beta-catenin pathway in triple negative breast cancer increases MMP7 in a PTEN dependent manner. PLoS One 8: e77425.

Didier G, Brezellec P, Remy E, Henaut A (2002) GeneANOVA-gene expression analysis of variance. Bioinformatics 18: 490-491.

Gao J, Aksoy BA, Dogrusoz U, Dresdner G, Gross B, Sumer SO, Sun Y, Jacobsen A, Sinha R, Larsson E, Cerami E, Sander C, Schultz N (2013) Integrative analysis of complex cancer genomics and clinical profiles using the cBioPortal. Sci Signal 6: pll.

Gong X, Yi J, Carmon KS, Crumbley CA, Xiong W, Thomas A, Fan X, Guo S, An Z, Chang JT, Liu QJ (2014) Aberrant RSPO3-LGR4 signaling in Keap1-deficient lung adenocarcinomas promotes tumor aggressiveness. Oncogene 34: 4692-4701.

Hayes MJ, Thomas D, Emmons A, Giordano TJ, Kleer CG (2008) Genetic changes of Wnt pathway genes are common events in metaplastic carcinomas of the breast. Clin Cancer Res 14: 4038-4044.

Hennessy BT, Giordano S, Broglio K, Duan Z, Trent J, Buchholz TA, Babiera G, Hortobagyi GN, Valero V (2006) Biphasic metaplastic sarcomatoid carcinoma of the breast. Ann Oncol 17: 605-613.

Howe LR, Brown AM (2004) Wnt signaling and breast cancer. Cancer Biol Ther 3: 36-41.

Ilmer M, Boiles AR, Regel I, Yokoi K, Michalski CW, Wistuba, Rodriguez J, Alt E, Vykoukal J (2015) RSPO2 enhances canonical Wnt signaling to confer stemness-associated traits to susceptible pancreatic cancer cells. Cancer Res 75: 1883-1896.

Jemal A, Siegel R, Ward E, Murray T, Xu J, Thun MJ (2007) Cancer statistics, 2007. CA Cancer J Clin 57: 43-66.

Jin YR, Yoon JK (2012) The R-spondin family of proteins: emerging regulators of WNT signaling. Int J Biochem Cell Biol 44: 2278-2287.

King TD, Suto MJ, Li Y (2012) The Wnt/beta-catenin signaling pathway: a potential therapeutic target in the treatment of triple negative breast cancer. J Cell Biochem 113: 13-18.

Klauzinska M, Baljinnyam B, Raafat A, Rodriguez-Canales J, Strizzi L, Greer YE, Rubin JS, Callahan R (2012) Rspo2/Int7 regulates invasiveness and tumorigenic properties of mammary epithelial cells. J Cell Physiol 227: 1960-1971.

Lallemand F, Mazars A, Prunier C, Bertrand F, Kornprost M, Gallea S, Roman-Roman S, Cherqui G, Atfi A (2001) Smad7 inhibits the survival nuclear factor kappaB and potentiates apoptosis in epithelial cells. Oncogene 20: 879-884.

Landemaine T, Jackson A, Bellahcene A, Rucci N, Sin S, Abad BM, Sierra A, Boudinet A, Guinebretiere JM, Ricevuto E, Nogues C, Briffod M, Bieche I, Cherel P, Garcia T, Castronovo V, Teti A, Lidereau R, Driouch K (2008) 
A six-gene signature predicting breast cancer lung metastasis. Cancer Res 68: 6092-6099.

Lehmann BD, Bauer JA, Chen X, Sanders ME, Chakravarthy AB, Shyr Y, Pietenpol JA (2011) Identification of human triple-negative breast cancer subtypes and preclinical models for selection of targeted therapies. J Clin Invest 121: 2750-2767.

Li Y, Welm B, Podsypanina K, Huang S, Chamorro M, Zhang X, Rowlands T, Egeblad M, Cowin P, Werb Z, Tan LK, Rosen JM, Varmus HE (2003) Evidence that transgenes encoding components of the Wnt signaling pathway preferentially induce mammary cancers from progenitor cells. Proc Natl Acad Sci USA 100: 15853-15858.

Lin SY, Xia W, Wang JC, Kwong KY, Spohn B, Wen Y, Pestell RG, Hung MC (2000) Beta-catenin, a novel prognostic marker for breast cancer: its roles in cyclin D1 expression and cancer progression. Proc Natl Acad Sci USA 97: 4262-4266.

Lindvall C, Evans NC, Zylstra CR, Li Y, Alexander CM, Williams BO (2006) The Wnt signaling receptor Lrp5 is required for mammary ductal stem cell activity and Wnt1-induced tumorigenesis. J Biol Chem 281: 35081-35087.

MacDonald BT, Tamai K, He X (2009) Wnt/beta-catenin signaling: components, mechanisms, and diseases. Dev Cell 17: 9-26.

Marangoni E, Vincent-Salomon A, Auger N, Degeorges A, Assayag F, de Cremoux P, de Plater L, Guyader C, De Pinieux G, Judde JG, Rebucci M, Tran-Perennou C, Sastre-Garau X, Sigal-Zafrani B, Delattre O, Dieras V, Poupon MF (2007) A new model of patient tumor-derived breast cancer xenografts for preclinical assays. Clin Cancer Res 13: 3989-3998.

Maubant S, Tesson B, Maire V, Ye M, Rigaill G, Gentien D, Cruzalegui F, Tucker GC, Roman-Roman S, Dubois T (2015) Transcriptome analysis of Wnt3a-treated triple-negative breast cancer cells. PLoS One 10: e0122333.

Meseure D, Vacher S, Lallemand F, Alsibai KD, Hatem R, Chemlali W, Nicolas A, De Koning L, Pasmant E, Callens C, Lidereau R, Morillon A, Bieche I (2016) Prognostic value of a newly identified MALAT1 alternatively spliced transcript in breast cancer. $\mathrm{Br} J$ Cancer 114: 1395-1404.

Morris GJ, Naidu S, Topham AK, Guiles F, Xu Y, McCue P, Schwartz GF, Park PK, Rosenberg AL, Brill K, Mitchell EP (2007) Differences in breast carcinoma characteristics in newly diagnosed African-American and Caucasian patients: a single-institution compilation compared with the National Cancer Institute's Surveillance, Epidemiology, and End Results database. Cancer 110: 876-884.

Nam JS, Park E, Turcotte TJ, Palencia S, Zhan X, Lee J, Yun K, Funk WD, Yoon JK (2007) Mouse R-spondin2 is required for apical ectodermal ridge maintenance in the hindlimb. Dev Biol 311: 124-135.

Robinson D, Van Allen EM, Wu YM, Schultz N, Lonigro RJ, Mosquera JM, Montgomery B, Taplin ME, Pritchard CC, Attard G, Beltran H, Abida W, Bradley RK, Vinson J, Cao X, Vats P, Kunju LP, Hussain M, Feng FY, Tomlins SA, Cooney KA, Smith DC, Brennan C, Siddiqui J, Mehra R, Chen Y, Rathkopf DE, Morris MJ, Solomon SB, Durack JC, Reuter VE, Gopalan A, Gao J, Loda M, Lis RT, Bowden M, Balk SP, Gaviola G, Sougnez C, Gupta M, Yu EY, Mostaghel EA, Cheng HH, Mulcahy H, True LD, Plymate SR, Dvinge H, Ferraldeschi R, Flohr P, Miranda S, Zafeiriou Z, Tunariu N, Mateo J, Perez-Lopez R, Demichelis F, Robinson BD, Schiffman M, Nanus DM, Tagawa ST, Sigaras A, Eng KW, Elemento O, Sboner A, Heath EI, Scher HI, Pienta KJ, Kantoff P, de Bono JS, Rubin MA, Nelson PS, Garraway LA, Sawyers CL, Chinnaiyan AM (2015) Integrative clinical genomics of advanced prostate cancer. Cell 161: 1215-1228.

Rognoni E, Widmaier M, Jakobson M, Ruppert R, Ussar S, Katsougkri D, Bottcher RT, Lai-Cheong JE, Rifkin DB, McGrath JA, Fassler R (2014) Kindlin-1 controls Wnt and TGF-beta availability to regulate cutaneous stem cell proliferation. Nat Med 20: 350-359.

Sarrio D, Rodriguez-Pinilla SM, Hardisson D, Cano A, Moreno-Bueno G, Palacios J (2008) Epithelial-mesenchymal transition in breast cancer relates to the basal-like phenotype. Cancer Res 68: 989-997.

Sarver AL, Murray CD, Temiz NA, Tseng YY, Bagchi A (2016) MYC and PVT1 synergize to regulate RSPO1 levels in breast cancer. Cell Cycle 15: 881-885.

Seshagiri S, Stawiski EW, Durinck S, Modrusan Z, Storm EE, Conboy CB, Chaudhuri S, Guan Y, Janakiraman V, Jaiswal BS, Guillory J, Ha C, Dijkgraaf GJ, Stinson J, Gnad F, Huntley MA, Degenhardt JD, Haverty PM, Bourgon R, Wang W, Koeppen H, Gentleman R, Starr TK, Zhang Z, Largaespada DA, Wu TD, de Sauvage FJ (2012) Recurrent R-spondin fusions in colon cancer. Nature 488: 660-664.

Shibamoto S, Higano K, Takada R, Ito F, Takeichi M, Takada S (1998) Cytoskeletal reorganization by soluble Wnt-3a protein signalling. Genes Cells 3: 659-670.

Shinmura K, Kahyo T, Kato H, Igarashi H, Matsuura S, Nakamura S, Kurachi K, Nakamura T, Ogawa H, Funai K, Tanahashi M, Niwa H, Sugimura H (2014) RSPO fusion transcripts in colorectal cancer in Japanese population. Mol Biol Rep 41: 5375-5384.

Teuliere J, Faraldo MM, Deugnier MA, Shtutman M, Ben-Ze'ev A, Thiery JP, Glukhova MA (2005) Targeted activation of beta-catenin signaling in basal mammary epithelial cells affects mammary development and leads to hyperplasia. Development 132: 267-277.

Watson AL, Rahrmann EP, Moriarity BS, Choi K, Conboy CB, Greeley AD, Halfond AL, Anderson LK, Wahl BR, Keng VW, Rizzardi AE, Forster CL, Collins MH, Sarver AL, Wallace MR, Schmechel SC, Ratner N, Largaespada DA (2013) Canonical Wnt/beta-catenin signaling drives human Schwann cell transformation, progression, and tumor maintenance. Cancer Discov 3: 674-689.

Weigelt B, Ng CK, Shen R, Popova T, Schizas M, Natrajan R, Mariani O, Stern MH, Norton L, Vincent-Salomon A, Reis-Filho JS (2015) Metaplastic breast carcinomas display genomic and transcriptomic heterogeneity (corrected). Mod Pathol 28: 340-351.

Xu WH, Liu ZB, Yang C, Qin W, Shao ZM (2012) Expression of dickkopf-1 and beta-catenin related to the prognosis of breast cancer patients with triple negative phenotype. PLoS One 7: e37624.

Yook JI, Li XY, Ota I, Hu C, Kim HS, Kim NH, Cha SY, Ryu JK, Choi YJ, Kim J, Fearon ER, Weiss SJ (2006) A Wnt-Axin2-GSK3beta cascade regulates Snaill activity in breast cancer cells. Nat Cell Biol 8: 1398-1406.

This work is published under the standard license to publish agreement. After 12 months the work will become freely available and the license terms will switch to a Creative Commons AttributionNonCommercial-Share Alike 4.0 Unported License.

Supplementary Information accompanies this paper on British Journal of Cancer website (http://www.nature.com/bjc) 